\title{
Mortality pattern in pediatric intensive care unit patients of a tertiary care teaching hospital: a retrospective analysis
}

\author{
Kalraiya $\mathbf{A}^{1}$, Kapoor $\mathbf{A}^{2}$, Singh $\mathbf{R}^{3}$ \\ ${ }^{1}$ Dr. Ashish Kalraiya, Assistant Professor, ${ }^{2}$ Dr. Anju Kapoor, Professor, ${ }^{3}$ Dr. Richa Singh, Residents; all authors are \\ attached with Department of Pediatrics, People's College of Medical Sciences \& Research Centre, Bhopal, Madhya \\ Pradesh, India.
}

Address for Correspondence: Dr. Ashish Kalraiya, Jawaherlal Nehru Cancer Hospital Campus, H.N.08, Idgah Hills, Bhopal, MP, Email: akalraiya@yahoo.com

\begin{abstract}
Background: A well functioning Pediatric Intensive Care Unit (PICU) contributes significantly in improving survival of critically sick children. Method: We retrospectively studied medical record of all children aged 1 month to 12 years old admitted in our PICU over a five years period. Data was collected in a predefined proforma that included age, gender, comorbidities and final diagnosis at the time of death. Patients who left the hospital against medical advice (LAMA) were also noted. Result: Out of 1767 admissions, 87 patients died with mortality rate of 4.92\%; male: female ratio of 2:1. $55.1 \%$ deaths belonged to 1 month to 5 years age group and $41(47.13 \%)$ cases died within 24 hours of admission. Central Nervous System diseases were the commonest cause of mortality (35\%) followed by Respiratory system diseases (28.73\%). Many critically sick patients (14.8\%) left the hospital against medical advice (LAMA). Conclusion: Mortality rate is quite low in our PICU; although high LAMA rate may be causing some bias in the result.
\end{abstract}

Keywords: Mortality; Pediatric Intensive Care Unit; PICU

\section{Introduction}

Intensive care unit has got a very important role in management of critically ill children. These patients who require continuous monitoring, hemodynamic support, respiratory support, advanced airway management are admitted in Pediatric Intensive Care Unit (PICU) to achieve better outcome [1].

Child mortality is a sensitive indicator of a country's development and evidence of its priorities and values. According to NFHS-4 (2015), under five mortality rate in India is 47/1000 live birth; in Madhya Pradesh it is higher [52 (urban) and 69(rural) per 1000 live birth [2]. Under nutrition is a very important contributor to underfive mortality.

Present study was conducted to review the mortality pattern over the last 5 year period in our PICU and to compare the results with published national and international data. This assessment can provide valuable

Manuscript received: $30^{\text {th }}$ November 2016

Reviewed: $08^{\text {th }}$ December 2016

Author Corrected: $18^{\text {th }}$ December 2016

Accepted for Publication: 27 $7^{\text {th }}$ December 2016 inputs in finding local disease pattern as well as cases requiring more intensive management with the aim to predict and reduce the mortality. The information thus obtained can also be used to assess the existing services and further improving the facilities for optimum patient care.

\section{Material and Methods}

We reviewed the medical records of all children aged 1 month to 12 years old who were admitted in PICU and died from July 2010 to June 2015. Ours' is a 5 bedded well equipped PICU unit in a teaching hospital (People's Hospital) attached to a medical college in central India.

Postgraduate pediatric residents do round the clock floor duty which is supervised and guided by senior residents and consultants in the department.

Data was collected from medical records in a predefined proforma that included age, gender, co morbidities and diagnosis at the time of death. Patient 
who left the hospital against medical advice (LAMA) was also noted.

The cause of death was classified (ICD-10 coding system) on basis of primary system involved along with associated co-morbidities. Study was approved by
Institutional Ethics Committee of People's College of Medical Sciences and Research Centre, Bhopal.

Data collected was entered into Excel sheet and analyzed by SPSS version 19 software. The results were shown as median, Inter Quartile Range (IQR), frequency and percentage.

\section{Result}

During five years of study period, there were 1767 PICU admissions and 87 deaths (mortality rate of $4.92 \%$ ). Out of 87 patients who died, male were $58(66.6 \%)$ as compared to $29(33.3 \%)$ females (M: F; 2:1).

Median age was 4 years with IQR of 6.6 years $\left(25^{\text {th }}\right.$ percentile 1.4 year; $75^{\text {th }}$ percentile 8.0 year; range 1 month- 12 years).

Table 1 shows distribution of deaths in different age group.

\section{Table-1: Age wise distribution of deaths}

\begin{tabular}{|l|l|}
\hline Age & Number of death \\
\hline 1Month to 1 year & $20(22.9 \%)$ \\
\hline 1year to 5 years & $28(32.2 \%)$ \\
\hline Above 5 years & $39(44.8 \%)$ \\
\hline
\end{tabular}

Out of 87 deaths, approximately half of them $(n=41 ; 47.13 \%)$ died within 24 hours of admission in PICU.

Twenty-four (27.59\%) cases succumbed to death between 24-48 hours and remaining 22 deaths $(25.29 \%)$ occurred after 48 hours (Table-2).

Table-2: Time interval from admission in PICU to death

\begin{tabular}{|l|l|}
\hline Interval from admission to death & Number (\%) \\
\hline Less than $24 \mathrm{hrs}$ & $41(47.13 \%)$ \\
\hline $24 \mathrm{hrs}$ to $48 \mathrm{hrs}$ & $24(27.59 \%)$ \\
\hline More than $48 \mathrm{hrs}$ & $22(25.29 \%)$ \\
\hline
\end{tabular}

Most common primary system involved leading to mortality was Central Nervous System ( $\mathrm{n}=31 ; 35 \%$ ) followed by Respiratory system $(\mathrm{n}=25 ; 28.73 \%)$ and Gastro-Intestinal system $(\mathrm{n}=15 ; 17.1 \%)($ Table- 3$)$.

Table-3: System wise distribution of mortality

\begin{tabular}{|l|l|l|}
\hline Primary system involved & ICD coding of system (Blocks) & Frequency (\%) \\
\hline Central Nervous System & G00-G98 & $31(35 \%)$ \\
\hline Cardiovascular system & I00-I99 & $10(11.49 \%)$ \\
\hline Respiratory system & J00-J99 & $25(28.73 \%)$ \\
\hline Gastrointestinal system & K00-K93 & $15(17.1 \%)$ \\
\hline Renal & N00-N99 & $3(3.44 \%)$ \\
\hline Poisoning & X40-X49 & $3(3.44 \%)$ \\
\hline
\end{tabular}

Different causes of mortality and co-morbid conditions are tabulated in table 4.

Common co-morbidities found were anemia in 35 (40.23\%) and sepsis in 36 (41.38\%) patients.

Large number of critically sick patients (14.8\%) left the hospital against medical advice (LAMA). 
Table-4: Causes of mortality and co-morbid conditions

\begin{tabular}{|l|l|}
\hline Causes & Frequency (\%) \\
\hline Pyogenic meningitis & $7(8.05)$ \\
\hline Tuberculous Meningitis & $3(3.45)$ \\
\hline Cerebral malaria & $8(9.19)$ \\
\hline Acute Febrile Encephalopathy & $8(9.19)$ \\
\hline Refractory status epilepticus & $5(5.75)$ \\
\hline Congenital Heart Disease & $6(6.89)$ \\
\hline Rheumatic Heart Disease & $1(1.15)$ \\
\hline Congestive Cardiac Failure with anemia & $2(2.29)$ \\
\hline Tubercular pericarditis & $1(1.15)$ \\
\hline Bacterial pneumonia & $22(25.29)$ \\
\hline Pulmonary Tuberculosis & $3(3.45)$ \\
\hline Acute Diarrhoea & $14(16.09)$ \\
\hline Abdominal tuberculosis & $1(1.15)$ \\
\hline Renal diseases & $3(3.45)$ \\
\hline Poisoning & $3(3.45)$ \\
\hline Failure ToThrive (up-to 5 years age) & $10 / 48(21)$ \\
\hline Anemia & $35(40.23)$ \\
\hline Sepsis & $36(41.38)$ \\
\hline
\end{tabular}

\section{Discussion}

We have 1767 admissions in PICU over 5 year period with 87 deaths ( mortality rate of $4.92 \%$ ) which is in accordance with various published studies (range; $2.1 \%$ - 7.1\% )[3-6]. Much higher rate of mortality (16.7\% $23.5 \%$ ) has been reported by other authors $[7,8,9]$.

We postulate that one probable reason of low mortality rate observed by us could be due to high LAMA (Left Against Medical Advice) rate of critically sick chidren from our PICU. Most of these patients leave the hospital either due to financial constraint or parents' perception that the child won't survive from current illness.

In present study, we observed that $55.1 \%$ deaths belonged to patients 1 month to 5 years age group, which is lower than reported by other studies $(72 \%$ $80 \%)[10,11]$. Higher proportion of male $(66.6 \%)$ dying in present observation is in accordance with the study done by Siddiqui et al $(60.5 \%)[1]$.

We observed that out of total 87 deaths, $47.13 \%$ cases died within 24 hours of admission in PICU which is in contrary with study done by Shashikala et al. They reported $16 \%$ deaths occurring within 24 hours of admission [10]. This reflects either a poor health seeking behavior of parents or very late referral from peripheral health centres.
We observed that neurological diseases were most common causes of mortality (35\%) followed by respiratory diseases $(28.73 \%)$. This observation is consistent with the study by Volakli et al [12] but contrary to other studies which reported either sepsis or pneumonia as most common causes of death [7, 13]. Singhal and colleagues in their study found respiratory condition (40\%) as most common cause of death in their PICU followed by neurological diseases (27\%) [14].

Apart from being a retrospective study, other limitations of present study include a high LAMA rate of critically sick patients from PICU (as we don't know the outcome of these sick children) and non-inclusion of pediatric surgical cases (they are admitted in surgical ICU after initial stabilization in PICU). A well functioning PICU reduces morbidity and mortality in critically sick children. Low mortality rate observed in present study shows quality management of our PICU patients; although high LAMA rate may be causing some bias in the result.

\section{Details of contributions:}

Dr Ashish Kalraiya: data collection, data analysis, literature search, drafted initial manuscript and approved the final manuscript before submission. 
Dr Anju Kapoor: Conceptualized the study, develop the study design, did literature search, data analysis, revised the manuscript and approved the final manuscript before submission.

Dr Richa Singh: Did data collection, literature search, reviewed the manuscript and approved the final manuscript before submission.

Funding: Nil, Conflict of interest: None initiated, Permission from IRB: Yes

\section{Reference}

1. Siddiqui Nu, Ashraf Z, Jurair H, Haque A. Mortality patterns among critically ill children in a Pediatric Intensive Care Unit of a developing country. Indian $\mathrm{J}$ Crit Care Med. 2015;19:147-50. Available at: http://www.ijccm.org/text.asp?2015/19/3/147/152756

2. Ministry of health and family welfare-National family health survey-(4), 2015-16. Available at: www.mohfw.nic.in

3. Blessing I. Lyoha A, Pooboni S K, Vuppali NKK. Morbidity Pattern and outcome of Patients admitted into a Pediatric Intensive Care unit in India. Indian Journal of Clinical Medicine. 2014; (5):1-5. DOI: 10.4137/IJCM.S13902

4. Eulmesekian PG, Pérez A, Minces PG, Ferrero H. Validation of pediatric index of mortality 2 (PIM2) in a single pediatric intensive care unit of Argentina. Pediatr Crit Care Med. 2007 Jan; 8(1): 54-7. DOI:10.1097/01.pcc.0000256619.78382.93

5. Choi KMS, Ng DKK, Wong SF, Kwok KL, Chow $\mathrm{PY}$, Chan $\mathrm{CH}$ et al. Assessment of the pediatric index of mortality (PIM) and the pediatric risk of mortality (PRISM) III score for prediction of mortality in a paediatric intensive care unit in Hong Kong. Hong Kong Med J. 2005; 11(2): 97-103.

6. Gemke RJ, Bonsel GJ.Comparative assessment of pediatric intensive care: a national multicenter study.
Pediatric Intensive Care Assessment of Outcome (PICASSO) Study Group. Crit Care Med. 1995 ;23(2):238-45.

7. Kapil D, Bagga A. The profile and outcome of patients admitted to a pediatric intensive care unit. Indian J Pediatr. 1993; 60(1):5-10.

8. Bellad R, Rao S, Patil VD, Mahantshetti NS. Outcome of intensive care unit patients using pediatric risk of mortality (PRISM) score. Indian Pediatr. 2009; 46(12):1091-92.

9. Hoque M S, Masud M A H, Uddin A N . Admission pattern and outcome in a paediatric intensive care unit of a tertiary care paediatric hospital in Bangladesh. DS (Child) H J. 2012; 28(1):14-19.

10. Shashikala V, Begum A, Kumar C S .Analysis of Mortality in PICU of A TertiaryCare Teaching Hospital in Telanganal. Journal of Dental and Medical Sciences. 2016; 15(5):07-12. DOI: 10.9790/0853-1504081317

11. George I O, Hart B A Alex, Briggs A I FrankMortality Pattern in Children. A Hospital Based Study in Nigeria: Int J Biomed Sci. 2009; 5(4):369-72. PMC3614794

12. Volakli E, Sdougka M, Tamiolaki M, Tsonidis C, Reizoglo M, Giala M. Demographic profile and outcome analysis of pediatric intensive care patients. HIPPOKRATIA. 2011;15(4):316-22.

13. Shah G S, Shah B K, Thapa A, Shah L, Mishra O P. Admission Patterns and Outcome in a Pediatric Intensive Care Unit in Nepal. British Journal of Medicine and Medical Research. 2014; 4(30): 4939-45.

14. Singhal D, Kumar N, Puliyel J M, Singh S K, Srinivas V. Prediction of mortility by application of PRISM score in intensive care unit. indian pediatr. 2001; 38 (7):714-19.

\section{How to cite this article?}

Kalraiya A, Kapoor A, Singh R. Mortality pattern in pediatric intensive care unit patients of a tertiary care teaching hospital: a retrospective analysis. J PediatrRes.2016;3(12):896-899.doi:10.17511/ijpr.2016.i12.08. 